\title{
EDUCATIONAL INFLUENCERS - WHAT CAN WE LEARN FROM THEM?
}

\author{
Paula Marcelo, Universidad de Sevilla, Spain
}

\begin{abstract}
Social networks have positioned themselves in today's society as the means through which teachers interact, communicate and share knowledge. The aim of the present study was to explore the format and contents present in Twitter publications that Spanish "educational influencers" use in their interaction with their followers. This investigation presents a qualitative design with a sample of 10 Spanish influencers of the educational scope, who were selected for having over 15,000 followers and over 5,000 tweets published. A qualitative analysis based on an inductive system of categories revealed that the topics that are most frequently addressed by these influencers are the complaints, concerns and reflections of teachers in online teaching, teaching strategies, activities and learning resources.
\end{abstract}

Keywords: Educational influencer, Social networks, Web 2.0, Informal learning, Educational technology, Social influence, Teacher training, Connected learning, Selfregulated learning.

\section{Introduction}

It is a very well-known fact that digital technologies have evolved exponentially throughout the years. Mobile devices, by incorporating recent technologies that make our everyday life easier, have evolved as much as the digital spaces and social networks through which we move and communicate nowadays, constituting a significant percentage of our leisure time. These also an important influence on the way in which knowledge is disseminated, thus generating new spaces for learning. This is known as informal learning, i.e., activities that involve the search for knowledge, understanding or abilities that take place without the intervention of curricular criteria imposed on teachers (Moore \& Klein, 2020).

Eraut (2004) highlighted that, unlike formal learning, informal learning has been poorly studied due to some characteristics that make it difficult to analyse. Other authors have 
Marcelo, $P$.

Educational influencers - What can we Learn from Them?

also analysed the influence of informal learning provided by teachers on the learnings acquired by students (Lai \& Smith, 2018), as well as the effect of this type learning on teachers' professional development, understood as continuous teacher training (Vezne \& Günbayi, 2016). The possibilities of self-regulated learning nowadays have multiplied. As is already known, any person with access to the Internet can learn anything they need, and not only in front of a computer, but through mobile devices (Sha, Looi, Chen, Seow, \& Wong, 2012).

Recent studies have focused on analysing how and why teachers use social networks both for their professional development, and to establish contact networks between other teaching professionals or affinity spaces (Barton \& Tusting, 2005). Recently, analyses carried out on the social network Twitter have made it possible to investigate some of the topics or hashtags that are most frequently used in the educational and academic sector (Carpenter et al., 2020). Twitter is not the only social network analysed. Other studies have sought to analyse how teachers make use of social networks such as Facebook (Hart \& Steinbrecher, 2011) and Twitter (Smith Risser, 2013). These studies focus on analysing, mainly, how social networks have become established as spaces for support and collaborative work between teachers (Kelly \& Antonio, 2016). We also find, with increasing frequency, studies that search the social network Pinterest for a space in which more and more teaching professionals share their work, their materials and ideas to take to the classroom (Schroeder et al., 2019).

It has been demonstrated that social networks, such as Twitter and Facebook, are meeting environments for people interested in learning a specific subject or field. Shen, Kuo, Ly, and Thi (2017) identified educational influencers and trends in social networks such as Twitter and Facebook by extracting information from their publications; they found that Twitter had the greatest frequency and amount of interactions compared to Facebook (Rehm \& Notten, 2016). Carpenter, Morrison, Craft, and Lee (2020) also studied the messages on the Instagram network. On the other hand, van Bommer and Lijekvist (2016) conducted a three-year-long study focused on showing the behaviour of math teachers in social networks; they confirmed that Facebook is still popular among teachers as a medium for their professional teaching development. Specifically, they showed 9 groups analysed in Facebook, each consisting of 2,000-11,000 members, which is a considerable number taking into account that they were private groups. 
Marcelo, $P$.

Educational influencers - What can we Learn from Them?

Therefore, we began this study by posing the following questions:

- What educational activities are carried out by educational influencers?

- What is the type of digital content produced by these influencers that generates the greatest popularity and interaction between their followers?

\section{Methodology}

This paper analyses the behaviour and interaction generated by a sample of individuals in Twitter who had a set of common characteristics in this social network. Twitter is one of the social networks with the largest number of followers nowadays, with 340 million users.

To analyse the profiles of the individuals that constitute our study sample, the Buzzsumo software was used, which is an online marketing analysis tool that allows carrying out advanced searches of people, profiles and most consumed and shared themes in the Internet, mainly in social networks. This tool allowed us to select a sample of influencers who represent profiles of high impact on their followers with their publications and interactions. Specifically, we focused on analysing profiles in Twitter, since it is a social network in which a large number of "educational influencers" converge. The analysis conducted through Buzzsumo was based on the following process:

44. Creation of an account using the Buzzsumo tool.

45. Screening of users in Twitter by keywords present in their biography and in their publications in this social network. The keywords used to conduct this classification were: Teaching, Iamateacher, Education, School and Learning.

After the analysis conducted through Buzzsumo, we obtained a sample of 64 educational influencers who were present in Twitter, of whom we analysed the 10 most representative influencers. We considered as representative profiles the ones with over 15,000 followers in Twitter and over 5,000 tweets published. The analysis of these influencers generated a category system that allowed establishing common criteria of such individuals in their interactions and publications, which were selected using the Buzzsumo tool.

To facilitate the subsequent analysis, the individuals were labelled in the following manner: Influencer 1. @xarxatic; Influencer 2. @ScientiaJMLN; Influencer 3. @Manu_Velasco; Influencer 4. @maestradepueblo; Influencer 5. @unicoos; Influencer 6. @smoll73; Influencer 7. @salvaroj; Influencer 8. @ftsaez; Influencer 9. @edusadeci; Influencer 10. @AyudaMaestros. 
Marcelo, $P$.

Educational influencers - What can we Learn from Them?

\section{Information gathering procedure}

Once the sample of 10 individuals was selected, a mass extraction was conducted, obtaining the last 3,200 tweets of each of these influencers in Twitter. These 3,200 tweets were distributed in an approximate period of 6 months, with differences between influencers in the number of tweets. The data extraction was carried out using the Google Chrome complement "Twlets", which allows exporting to an Excel worksheet up to 3,200 tweets of users in this social network.

We obtained a total of 32,000 publications from the selected individuals, which were then categorised. To this end, a category system was inductively developed, which allowed classifying the type and content of the publications generated in Twitter. The aim of this analysis was to specify which contents and formats are most frequently used by educational influencers to generate this interaction with their followers.

\section{Category system}

Due to the lack of studies in this topic, we developed an inductive category system, following the steps described below for the creation of the categories, as recommended by Miles and Huberman (1984):

46. Reading of all the extracted tweets from each of the 10 selected influencers;

47. In parallel to step 1 reading, initial labelling of the topics that appeared;

48. Grouping of the topics based on theme similarity;

49. Definition of the categories;

50. Application of the category system to an initial sample,

51. Filtering of the category system;

52. Final category system;

53. Redefinition of some categories during the data analysis process.

The final category system consists of two dimensions: (a) Type of generated publications and (b) Content of the generated publications. Regarding the second dimension, we classified up to 9 categories that refer to the content tackled in the analysed publication: (a) Personal view, which refers to personal and individual aspects of the influencer; (b) Inclusion and diversity; (c) Emotional and affective education; (d) Subjects and contents; (e) Privacy and safety; (f) Innovative methodologies; (g) Teaching innovation; (h) School management and (i) Teaching. 
Marcelo, $P$.

Educational influencers - What can we Learn from Them?

\section{Data analysis}

We conducted a data analysis that addressed the content of the publications related to several elements. Firstly, we find personal view, which is characterised by publications that contain reflections, opinions, personal acknowledgements, recommendations, collaboration messages to other teachers, and anecdotes or experiences. These publications contain rather personal messages, and they are aimed at impacting followers by showing subjective positions toward a specific topic related to education.

Table 1 shows that the most frequent item is that of objections (35\%). This item is also one of the most striking in this study, as it shows expressions such as the one presented by Individual 4 (@maestradepueblo) “Will we have to teach in the school yard? -Well, you will be allowed to go inside a pub very soon", or "I see you complaining a lot about the digital competence of students these days”.

Table 1: Results in the category of personal view

\begin{tabular}{lcccccccccc}
\hline Personal view & Infl 1 & Infl 2 & Infl 3 & Infl 4 & Infl 5 & Infl 6 & Infl 7 & Infl 8 & Infl 9 & Infl 10 \\
\hline Help and collaboration & $11 \%$ & $6 \%$ & $31 \%$ & $5 \%$ & $17 \%$ & $14 \%$ & $6 \%$ & $14 \%$ & $1 \%$ & $27 \%$ \\
Publicity & $4 \%$ & $16 \%$ & & & $12 \%$ & & & & & $4 \%$ \\
Reflections & $22 \%$ & $20 \%$ & $30 \%$ & $13 \%$ & $18 \%$ & $16 \%$ & $41 \%$ & $37 \%$ & $10 \%$ & $7 \%$ \\
Objections & $51 \%$ & $33 \%$ & $38 \%$ & $60 \%$ & $12 \%$ & & $20 \%$ & $35 \%$ & $8 \%$ & \\
Interviews & & $6 \%$ & & & & $5 \%$ & $7 \%$ & & $6 \%$ & \\
Acknowledgements & $7 \%$ & $35 \%$ & $16 \%$ & $6 \%$ & $4 \%$ & & $15 \%$ & $5 \%$ & $18 \%$ & $20 \%$ \\
Anecdotes and experiences & $5 \%$ & $3 \%$ & $2 \%$ & $6 \%$ & $7 \%$ & $6 \%$ & $4 \%$ & & $11 \%$ & $24 \%$ \\
Advices & $14 \%$ & & $6 \%$ & & $8 \%$ & $69 \%$ & $10 \%$ & $4 \%$ & $1 \%$ & \\
Curiosities & & $5 \%$ & & & $17 \%$ & & & & $34 \%$ & \\
Humour & $2 \%$ & & & $36 \%$ & & & & & $13 \%$ & \\
News about education and policies & $25 \%$ & $13 \%$ & $13 \%$ & $38 \%$ & $22 \%$ & & $10 \%$ & $17 \%$ & $12 \%$ & $18 \%$ \\
\hline
\end{tabular}

Following the most frequent subcategories, we find the item related to reflections (22\%). This item has comments such as "We are living an epidemic of critical thinking decline, that's why fake news are growing" and "Today we must and can only teach through happiness".

The next item was related to the publications about inclusion and diversity. Table 2 shows that the influencer with the greatest contribution including contents about inclusion and diversity was Influencer 8 (@ftsaez).

Table 2: $\quad$ Results of the category of inclusion and diversity

\begin{tabular}{lccccccccccc}
\hline & $\operatorname{Infl} 1$ & $\operatorname{Infl} 2$ & $\operatorname{Infl} 3$ & $\operatorname{Infl} 4$ & $\operatorname{Infl} 5$ & $\operatorname{Infl} 6$ & $\operatorname{Infl} 7$ & $\operatorname{Infl} 8$ & $\operatorname{Infl} 9$ & $\operatorname{Infl} 10$ & TOTAL \\
\hline Inclusion and diversity & $18 \%$ & $3 \%$ & & $3 \%$ & $2 \%$ & $3 \%$ & $3 \%$ & $52 \%$ & $16 \%$ & $2 \%$ & $100 \%(3,776)$ \\
\hline
\end{tabular}

There are also messages related to the application of some methodology considered as innovative, such as gamification, visual thinking, augmented reality, mixed reality, virtual reality, robotics and Big Data. Table 3 shows the publishing frequency of each of the analysed individuals, a topic that has been present in all their contributions, although not 
Marcelo, $P$.

Educational influencers - What can we Learn from Them?

in a remarkable way "How to teach the verb tenses through cooperative learning" (Influencer 6, @smoll73).

Table 3: $\quad$ Results of the category of innovative methodologies

\section{Innovative}

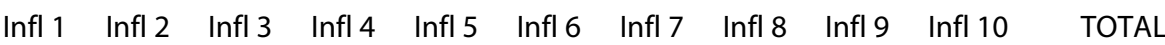

methodologies

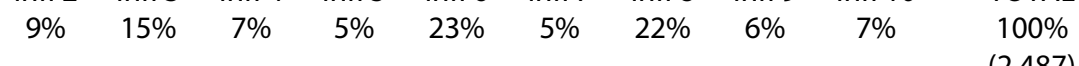

After this item, we analysed messages related to teaching innovation in environments associated with teacher training and digital competence. Table 4 shows that the field of teachers' professional development was approached in $64 \%$ of the tweets by 7 of the analysed influencers. Regarding educational technology, 59\% of the tweets of 7 influencers contained comments related to this topic.

Table 4: $\quad$ Results of the category of teaching innovation

\begin{tabular}{|c|c|c|c|c|c|c|c|c|c|c|}
\hline Teaching innovation & Infl 1 & $\operatorname{lnfl} 2$ & $\operatorname{lnfl} 3$ & $\operatorname{lnfl} 4$ & $\operatorname{lnfl} 5$ & $\operatorname{lnfl} 6$ & $\operatorname{lnfl} 7$ & $\operatorname{lnfl} 8$ & $\operatorname{lnfl} 9$ & $\operatorname{lnfl} 10$ \\
\hline $\begin{array}{l}\text { Teachers' professional } \\
\text { development }\end{array}$ & $80 \%$ & $100 \%$ & $55 \%$ & $49 \%$ & & $67 \%$ & $52 \%$ & $40 \%$ & & \\
\hline Educational technology & $74 \%$ & & $80 \%$ & $78 \%$ & $10 \%$ & $33 \%$ & $48 \%$ & $60 \%$ & & \\
\hline
\end{tabular}

Next, we analysed aspects related to school management, understood in terms of managing the courses, the schools, the beginning of the courses and the teachers that work in them. Table 5 shows the outstanding participation of Influencer 4 (@maestradepueblo) in this category: "We need more substitute teachers to begin with students, more material resources, etc. Solution? Increasing the number of hours of some subjects".

Table 5: $\quad$ Results of the category of school management

\begin{tabular}{cccccccccccc}
\hline & $\operatorname{Infl} 1$ & $\operatorname{Infl} 2$ & $\operatorname{Infl} 3$ & $\operatorname{Infl} 4$ & $\operatorname{Infl} 5$ & $\operatorname{Infl} 6$ & $\operatorname{Infl} 7$ & $\operatorname{Infl} 8$ & $\operatorname{Infl} 9$ & $\operatorname{Infl} 10$ & TOTAL \\
\hline School management & $22 \%$ & & $5 \%$ & $48 \%$ & & $7 \%$ & $2 \%$ & $7 \%$ & $9 \%$ & & $100 \%(2,964)$ \\
\hline
\end{tabular}

Lastly, we approached a very representative category with respect to this study, i.e., teaching. This category refers to teaching strategies that teachers provide in their messages, aspects related to online teaching, learning videos, teaching design digital tools, etc. As is shown in Table $6,46 \%$ of the tweets have approached topics related to online teaching, with Influencer 1 (@xarxatic) showing the greatest contribution to this topic in his posts: "Run away from Zoom!", "not all students will be able to follow those wonderful online classes”.

Table 6: Results of the category of teaching.

\begin{tabular}{|c|c|c|c|c|c|c|c|c|c|c|}
\hline Teaching & $\operatorname{lnfl} 1$ & $\operatorname{lnfl} 2$ & $\operatorname{lnfl} 3$ & $\operatorname{lnfl} 4$ & $\operatorname{lnfl} 5$ & $\operatorname{lnfl} 6$ & $\operatorname{lnfl} 7$ & $\operatorname{lnfl} 8$ & $\operatorname{lnfl} 9$ & $\operatorname{lnfl} 10$ \\
\hline Online teaching & $79 \%$ & $84 \%$ & $27 \%$ & $31 \%$ & $44 \%$ & & & $72 \%$ & $7 \%$ & $26 \%$ \\
\hline Videos about learning & & & & & $60 \%$ & & & $6 \%$ & $78 \%$ & \\
\hline Digital tools & $37 \%$ & & $61 \%$ & $26 \%$ & $4 \%$ & $12 \%$ & & $2 \%$ & $7 \%$ & $39 \%$ \\
\hline Learning activities and resources & $21 \%$ & $50 \%$ & $31 \%$ & & $18 \%$ & $22 \%$ & & $7 \%$ & $15 \%$ & $37 \%$ \\
\hline Teaching strategies & $10 \%$ & & & $10 \%$ & $3 \%$ & $65 \%$ & $53 \%$ & $2 \%$ & & \\
\hline Curriculum & & & & & & & $17 \%$ & $6 \%$ & & \\
\hline Evaluation & $13 \%$ & $5 \%$ & $14 \%$ & $59 \%$ & $13 \%$ & $6 \%$ & $31 \%$ & $14 \%$ & & $11 \%$ \\
\hline
\end{tabular}


Marcelo, $P$.

Educational influencers - What can we Learn from Them?

\section{Conclusions}

Throughout this paper, it was observed that the content generated in social networks by individuals with the capacity to influence others can be considered as an opportunity to create new spaces for the exchange of knowledge and learning.

Regarding the categories with greater space, time and importance in this study, we must mainly focus on two. The first category refers to the personal view of the educational influencers on their perceptions, reflections, objections and acknowledgements. The second category refers to teaching, which showed concerns and reflections of teachers about complex aspects such as online teaching, teaching strategies, learning activities and resources, and the evaluation of learnings.

The main objective of this study was to determine the type of content and elements that were present in the publications of the 10 educational influencers with greatest impact at present. Elements such as objections, educational technology, reflections, subjects and contents, digital tools, and emotional and affective education were topics that appeared frequently in our analysis and will be studied in future research lines.

Knowing how each of the influential teachers are and what they share helps us to better understand how these informal structures of learning appear and consolidate in digital environments.

\section{References}

Barton, D., \& Tusting, K. (2005). Beyond Communities of Practice: Language Power and Social Context - Google Libros. Retrieved from https://books.google.es/books?id=wkbJa_mYIicC\&lpg=PA214\&lr\&hl=es\&pg=PP1\#v $=$ onepage $\& \mathrm{q} \& \mathrm{f}=$ false

van Bommel, J., \& Liljekvist, Y. (2016). Teachers' informal professional development on social media and social network sites: when and what do they discuss? Paper presented at the ERME Topic Conference on Mathematics teaching, resources and teachers' professional development, Berlin, Germany.

Carpenter, J. P., Morrison, S. A., Craft, M., \& Lee, M. (2020). How and why are educators using Instagram? Teaching and Teacher Education, 96, 103149. https://doi.org/10.1016/j.tate.2020.103149

Carpenter, J., Tani, T., Morrison, S., \& Keane, J. (2020). Exploring the landscape of educator professional activity on Twitter: an analysis of 16 education-related Twitter hashtags. Professional Development in Education, 1-22.

https://doi.org/10.1080/19415257.2020.1752287 
Marcelo, $P$.

Educational influencers - What can we Learn from Them?

Eraut, M. (2004). Informal learning in the workplace. Studies in Continuing Education, 26(2), 247-273.

Kelly, N., \& Antonio, A. (2016). Teacher peer support in social network sites. Teaching and Teacher Education, 56, 138-149. https://doi.org/10.1016/j.tate.2016.02.007

Kyndt, E., Gijbels, D., Grosemans, I., \& Donche, V. (2016). Teachers' Everyday Professional Development: Mapping Informal Learning Activities, Antecedents, and Learning Outcomes. Review of Educational Research, 86, 1111-1150.

Lai, K. W., \& Smith, L. A. (2018). University educators' perceptions of informal learning and the ways in which they foster it. Innovative Higher Education, 43(5), 369-380.

Lam, J., Yau, J., \& Cheung, S. K. (2010). A review of mobile learning in the mobile age. In P. Tsang, S.K.S. Cheung, V.S.K. Lee, \& R. Huang (Eds.), Hybrid learning (pp. 306-315). Berlin Heidelberg: Springer

Moore, A. L., \& Klein, J. D. (2020). Facilitating Informal Learning at Work. TechTrends: Linking Research and Practice to Improve Learning, 64(2), 219-228

Rehm, M., \& Notten, A. (2016). Twitter as an informal learning space for teachers!? The role of social capital in Twitter conversations among teachers. Teaching and Teacher Education, 60, 215-223

Schroeder, S., Curcio, R., \& Lundgren, L. (2019). Expanding the Learning Network: How Teachers Use Pinterest. Journal of Research on Technology in Education, 51(2), 166186. https://doi.org/10.1080/15391523.2019.157335

Sha, L., Looi, C.-K., Chen, W., Seow, P., \& Wong, L.-H. (2012). Recognizing and measuring self-regulated learning in a mobile learning environment. Computers in Human Behavior, 28, 718-728.

Shen, C. W., Kuo, C. J., Ly, M., \& Thi, P. (2017). Analysis of social media influencers and trends on online and mobile learning. International Review of Research in Open and Distributed Learning, 18(1), 208-224.

Witecki, G., \& Nonnecke, B. (2015). Engagement in digital lecture halls: A study of student course engagement and mobile device use during lecture. Journal of Information Technology Education: Research, 14, 73-90.

Vezne, R., \& Günbayi, I. (2016). The Effect of Informal Learning on Teachers' Professional Development: A Case Study. Online Submission, 7(3), 11-22. 